\title{
Before-and-After Field Investigation of the Effects on Pollutant Emissions of Replacing a Signal-Controlled Road Intersection with a Roundabout
}

\author{
Claudio Meneguzzer, Massimiliano Gastaldi $(\mathbb{D}$, and Rosa Arboretti Giancristofaro \\ Department of Civil, Environmental and Architectural Engineering, University of Padova, Via Marzolo 9, 35131 Padova, Italy
}

Correspondence should be addressed to Massimiliano Gastaldi; massimiliano.gastaldi@unipd.it

Received 23 November 2017; Accepted 13 March 2018; Published 10 May 2018

Academic Editor: Antonio Comi

Copyright (c) 2018 Claudio Meneguzzer et al. This is an open access article distributed under the Creative Commons Attribution License, which permits unrestricted use, distribution, and reproduction in any medium, provided the original work is properly cited.

\begin{abstract}
The purpose of this study is to assess the effects on air pollution that may derive from replacing a signal-controlled intersection with a roundabout, using a before-and-after approach. Based on field data collected with a test car instrumented with a Portable Emission Measurement System, the two intersection configurations were compared in terms of emissions of $\mathrm{CO}_{2}, \mathrm{CO}$ and $\mathrm{NO}_{X}$. The existence of significant differences in emissions between the two types of control was assessed by means of a statistical technique known as two-sample biaspect permutation test. In addition, focusing on trips carried out in peak traffic conditions, binary logistic regression models were developed to identify the factors that significantly affect vehicular emissions and to quantify their effect. The findings of our analyses show that emissions of $\mathrm{CO}_{2}$ and $\mathrm{CO}$ are generally lower for the roundabout than for the signal-controlled intersection, while an opposite result arises for $\mathrm{NO}_{X}$ emissions. As far as other influential factors are concerned, trip direction (reflecting site-specific conditions) and driver behavior have a considerable impact on the emissions of all three pollutants.
\end{abstract}

\section{Introduction and Research Objectives}

The impact on air quality of pollutant emissions produced by road traffic has become a central issue in the context of transportation system analysis and policy. Vehicular emissions depend on traffic, road, and vehicle characteristics, on atmospheric conditions, and on driving behavior, and it is well known that intersections are typically pollution "hotspots" because of the concentration of highly emitting modal activities (in particular vehicle acceleration) in their proximity $[1,2]$. Intersection geometric configuration and type of control play a major role in determining the pattern of traffic flow interruption and thus the associated vehicular emissions.

Roundabouts are increasingly used worldwide and are often built to replace intersections previously controlled by traffic signals or stop signs. While several studies have shown that roundabouts can improve safety and, at least in certain flow ranges, the operational performance compared to other types of intersection control [3], there is no general agreement regarding their ability to reduce vehicular emissions and fuel consumption. Analyses specifically focusing on this issue have often reached opposite conclusions, and therefore it seems valuable to provide additional evidence regarding the comparative environmental performance of roundabouts versus other types of intersections.

The main aim of this study is to investigate the effects on air pollution of replacing a signal-controlled intersection with a roundabout, using a before-and-after approach based on field measurements of vehicular emissions. To this end, data have been collected using an instrumented vehicle at a real road intersection where a traffic signal has been converted to a roundabout, so as to allow to compare the two forms of control in terms of emissions of selected pollutants. The research described in this paper represents a development of previous work by the authors: Meneguzzer et al. [4] proposed to apply cluster analysis to characterize intersections by type of control based on time-in-mode composition of trips, average trip duration, and emissions, while Gastaldi et al. [5] focused on the effect of intersection control type on 
carbon dioxide emissions and concluded that converting a signal-controlled intersection to a roundabout may lead to a decrease in emissions of this pollutant.

The contribution of the study described in this paper may be valuable for two reasons. First, the question of whether the type of intersection control has a significant impact on vehicular pollution is investigated on the basis of a before-and-after field experiment at a real intersection rather than using simulation tools, the latter being the approach most frequently adopted in previous studies on the subject. Second, in the statistical analysis of the experimental data we propose the use of a method that, to our knowledge, has not been employed by others in this area of research. More specifically, the existence of statistically significant differences in vehicular emissions between the two types of intersection is assessed by means of two-sample biaspect permutation tests, a nonparametric method that allows simultaneously detecting differences in location and variability characteristics of the distributions of the observations for the two forms of control.

The paper is organized as follows. Section 2 provides a brief summary of previous work on vehicular emissions at or near road intersections, with specific attention to the effect of different kinds of control. Section 3 deals with the data collection process, describing the study site, the characteristics of the test vehicle and equipment, and the methods adopted to gather and treat the experimental data. Section 4 reports the results of the statistical analyses carried out in order to compare emissions under traffic signal versus roundabout control. Conclusions and possible future developments of the research are presented in Section 5.

\section{Literature Review}

Several studies dealing with the analysis of vehicular emissions at road intersections can be found in the literature, some of them focusing in particular on the effect of the type of traffic control on emissions. Two main approaches have been adopted in these studies: either a modeling approach combining traffic microsimulation and vehicular emission models or an experimental approach based on direct field measurement of emission data.

Hydén and Várhelyi [6] and Várhelyi [7] found that small roundabouts replacing unsignalized intersections caused a limited increase in $\mathrm{CO}$ and $\mathrm{NO}_{X}$ emissions, but when replacing signal-controlled intersections they led to a considerable decrease of emissions of the same pollutants. Zuger et al. [8] used an instrumented vehicle to carry out a before-after study on five intersections that had been converted to roundabouts and suggested that the effect of the type of control on emissions depended on local conditions and time of day, so that no general conclusion could be reached. However, a tendency of roundabouts to perform better than signalized intersections and worse than unsignalized intersections was observed in their study.

Unal et al. [19] studied the impact of traffic signal timing and coordination on vehicular emissions using onroad measurements and showed the effectiveness of signal coordination as a strategy for reducing emissions. Similar conclusions have been reached by Tao et al. [20], who stressed that the environmental benefits of coordination may depend significantly on driving behavior, and by other more recent studies [21,22].

The relationship between vehicle dynamics and emissions for single-lane roundabouts was analyzed by Coelho et al. [23] based on synthetic speed profiles and their frequency distribution as a function of congestion levels. Their results indicate that emissions generally increase with conflicting traffic under conditions of queuing and also as a function of the difference between cruise and circulating speeds. Salamati et al. [24] investigated the effect of the approach lane on emissions at multilane roundabouts, and concluded that the relative magnitude of the pollutants emitted by vehicles in different lanes was significantly affected by the level of congestion. Mudgal et al. [25] studied speed and acceleration profiles at a roundabout in order to evaluate the effect of driving behavior on vehicular emissions and found significant differences across drivers.

Mandavilli et al. [9] used the aaSIDRA 2.0 software to analyze emissions at six intersections where roundabouts had replaced two-way or four-way stop control. They found a statistically significant decrease in $\mathrm{CO}, \mathrm{CO}_{2}, \mathrm{NO}_{X}$, and $\mathrm{HC}$ emissions as a result of roundabout installation. Similar results were obtained in a study by Vlahos et al. [10] regarding the conversion of all-way stop-controlled intersections into roundabouts. More recently, Yang et al. [11] have found that converting a two-way stop-controlled intersection into a roundabout can reduce vehicle emissions under most traffic volume scenarios.

Ahn et al. [12] evaluated the fuel consumption and emission impacts of a high-speed roundabout in comparison with two-way stop control and signal control using traffic microsimulation and microscopic emission models and concluded that the roundabout does not necessarily reduce emission levels compared to the other forms of intersection control. Chamberlin et al. [13] considered a case of intersection control change from pretimed traffic signal to roundabout and suggested that the latter may perform worse than the former in terms of $\mathrm{CO}$ and $\mathrm{NO}_{X}$ emissions under both light and congested traffic conditions.

Hallmark et al. [14] used a vehicle instrumented with a Portable Emission Measurement System (PEMS) to collect on-road pollution data and compared the air quality impacts of different types of intersections (signal-controlled, fourway stop, and roundabout). Based on the analysis of $\mathrm{CO}_{2}$, $\mathrm{CO}, \mathrm{NO}_{X}$, and $\mathrm{HC}$ emissions, the authors concluded that roundabouts do not necessarily perform better than the other forms of intersection control. They also suggested that the results varied by type of pollutant and stressed the effect of driver behavior.

Papson et al. [26] used a time-in-mode analysis to estimate vehicular emissions at a signalized intersection under different traffic scenarios. Their results show that emissions are much less sensitive to congestion than control delay, and that significant environmental benefits can be expected from strategies (like signal coordination) that reduce the time spent by vehicles in the acceleration mode. 
Jackson and Rakha [15] studied a "generalized" four-leg intersection with uniform approach demands. They compared emissions of $\mathrm{CO}, \mathrm{CO}_{2}, \mathrm{HC}$, and $\mathrm{NO}_{X}$ under four types of traffic control (roundabout, signal control, two-way stop control, and all-way stop control) using the INTEGRATION software and found that roundabouts can minimize the emissions of the above pollutants only in certain ranges of approach demands and turn percentages.

Vasconcelos et al. [27] compared different roundabout configurations (single-lane, two-lane and turbo-roundabout) using microscopic simulation and concluded that a two-lane roundabout is a better choice if the priority is the reduction of $\mathrm{CO}_{2}$ and $\mathrm{NO}_{X}$ emissions, while for other local pollutants (CO and $\mathrm{HC}$ ) turbo-roundabouts appear to offer a better performance.

Gastaldi et al. [16] used the microsimulation software SParamics and instantaneous emission models for $\mathrm{NO}_{X}, \mathrm{PM}_{10}$, and total carbon to analyze a real four-leg intersection where a roundabout had replaced a fixed-time traffic signal. They found that the roundabout generally outperformed the fixedtime traffic signal in terms of vehicle emissions but noted that the difference between the two types of control was smaller in terms of environmental impacts than in terms of operational traffic performance.

An empirically supported macroscopic method for comparing vehicular emissions at roundabouts and signalized intersections was proposed by Salamati et al. [17]. Based on VSP (Vehicle Specific Power) as a key explanatory variable, the method allows estimation of emissions of $\mathrm{NO}_{X}, \mathrm{CO}$, $\mathrm{CO}_{2}$, and $\mathrm{HC}$ taking into account several factors, including demand-to-capacity ratio, signal timing, and signal progression characteristics. Results of an application to a real case indicate that roundabouts tend to be less polluting than traffic signals under low demand-to-capacity ratios; however, when demand approaches capacity, signalized intersections with favorable progression generate lower emissions than roundabouts.

The environmental impact of a sequence of roundabouts in a corridor was analyzed by Fernandes et al. [18], who found that, at the arterial level, roundabouts performed better than traffic signals but worse than stop controls in terms of emissions. Fernandes et al. [28] also investigated the spatial distribution of emissions along a roundabout corridor and identified emission "hotspots" for the cases of equally and unequally spaced intersections. A recent development of this line of research [29] focuses on vehicular emissions along turbo-roundabout corridors in comparison with conventional two-lane roundabout corridors.

The analysis of pollution at signal-controlled intersections has also been approached from a "design" viewpoint; for example, Li et al. [30] proposed an optimization method for signal timing taking into account vehicle delay, number of stops, and emissions of $\mathrm{CO}_{2}, \mathrm{CO}, \mathrm{NO}_{X}$, and HC. More recent examples of studies on signal control with traffic and environmental objectives are the papers by Song et al. [31] and Calle Laguna et al. [32].

Among the studies reviewed in the present section, those concerning comparative analyses of emissions under different types of intersection control are of major interest to our research and are summarized in Table 1. In conclusion, we observe that the majority of previous studies dealing with the analysis of pollution produced by traffic at intersections have made use of simulation models, which emphasizes the need for additional research contributions based on direct field measurements of vehicular emissions.

\section{Data Collection and Processing}

Data were collected at a four-leg road intersection where a roundabout has replaced a traffic signal (Figure 1). The intersection is located in the urban area of Vicenza, in the Veneto region, Italy. Basic traffic signal and roundabout characteristics are reported in Tables 2 and 3, respectively.

Field tests were carried out with a Fiat Panda SparkIgnition (SI) bifuel (gasoline/natural gas) passenger car complying with Euro 4 emission standards. Fiat Panda is Italy's best-selling car and it can be considered a point of reference of the city-car segment in Europe. The emissive behavior of this car in urban areas has been characterized by Meccariello et al. [33]. It is equipped with an Original Equipment Manufacturer (OEM) three-way catalyst (TWC), which catalyzes the reactions between oxidizing $\left(\mathrm{O}_{2}\right.$ and $\mathrm{NO}_{X}$ ) and reducing ( $\mathrm{CO}$ and $\mathrm{HC}$ ) species present in the exhaust. During the on-road tests the car was fuelled only with commercial gasoline.

On-road measurements of vehicle activity and emissions on a second-by-second basis can be obtained using Portable Emissions Measurement Systems (PEMS). Several studies have shown the effectiveness of PEMS as tools for collecting emission data that are representative of actual and typical vehicle use; see, for example, [34, 35].

A Semtech PEMS from Sensors Inc. was installed onboard the test car for emission measurement. This device can produce the vehicle's instantaneous emission profile and estimate the level of emissions produced while the car is running. The equipment consists of a tailpipe attachment, heated exhaust lines, a Pitot tube for measuring the exhaust mass flow and temperature, exhaust gas analyzers, a GPS Garmin 16x, sensors for ambient temperature and humidity, and exhaust pipelines. GPS and weather station were installed outside on the roof of the vehicle. An On-Board Diagnostics (OBD) Matrix from Texa, capable of communicating with the Electronic Control Unit (ECU) of the vehicle, was connected to the car's OBD socket, in order to collect with $1 \mathrm{~Hz}$ frequency the following parameters: vehicle speed, rpm, gear ratio, and engine load. A video camera was also installed onboard to record video images of traffic from the viewpoint of the car driver. All parameters were measured with a time resolution of one second. Emissions were measured only in hot conditions, after a 45 -minute preconditioning period necessary to let PEMS reach all the set-points.

Two data collection campaigns were conducted along Viale Mazzini, an urban corridor located in the city of Vicenza, Italy, before (April 1-3, 2014) and after (April $14-16,2015)$ the conversion of a signalized intersection to a roundabout (Figure 1). In both cases data were collected over three consecutive weekdays (Tuesday to Thursday). Morning and evening test sessions were scheduled in two time slots: 
TABLE 1: Summary of selected studies comparing vehicular emissions at intersections under different types of control (numbers in first column correspond to cited references) [4].

\begin{tabular}{|c|c|c|c|}
\hline Reference & $\begin{array}{l}\text { Method for estimation of } \\
\text { emissions }\end{array}$ & Pollutants considered & Main findings \\
\hline$[6,7]$ & $\begin{array}{l}\text { Emission factors for observed } \\
\text { speeds and accelerations }\end{array}$ & $\mathrm{CO}, \mathrm{NO}_{x}$ & $\begin{array}{l}\text { Emissions for small RBT are lower than for SIG } \\
\text { and slightly higher than for UNSIG. }\end{array}$ \\
\hline$[8]$ & Instrumented vehicle & $\mathrm{CO}, \mathrm{CO}_{2}, \mathrm{NO}_{x}$ & $\begin{array}{l}\text { Results are dependent on local conditions and } \\
\text { time of day; emissions tend to be generally } \\
\text { lower for RBT than for SIG and higher for RBT } \\
\text { than for UNSIG. }\end{array}$ \\
\hline$[9]$ & aaSIDRA 2.0 software & $\mathrm{CO}, \mathrm{CO}_{2}, \mathrm{HC}, \mathrm{NO}_{x}$ & $\begin{array}{l}\text { Emissions are reduced following conversion of } \\
\text { stop-controlled intersections to RBTs. }\end{array}$ \\
\hline$[10]$ & aaSIDRA 2.1 software & $\mathrm{CO}, \mathrm{CO}_{2}, \mathrm{HC}, \mathrm{NO}_{x}$ & $\begin{array}{l}\text { Emissions of all considered pollutants are lower } \\
\text { for RBT than for AWSC. They are also lower } \\
\text { for RBT than for SIG, but only up to a } \\
\text { threshold of total intersection demand volume. }\end{array}$ \\
\hline$[11]$ & VISSIM software & $\mathrm{CO}, \mathrm{NO}_{x}, \mathrm{VOC}$ & $\begin{array}{l}\text { Converting TWSC into RBT can reduce vehicle } \\
\text { emissions under most traffic volume scenarios. }\end{array}$ \\
\hline$[12]$ & $\begin{array}{c}\text { INTEGRATION and VISSIM } \\
\text { software; VT-Micro and CMEM } \\
\text { emission models } \\
\end{array}$ & $\mathrm{CO}, \mathrm{CO}_{2}, \mathrm{HC}, \mathrm{NO}_{x}$ & $\begin{array}{l}\text { Emissions of all considered pollutants are } \\
\text { higher for RBT than for SIG and TWSC. }\end{array}$ \\
\hline$[13]$ & $\begin{array}{l}\text { Paramics software; MOVES and } \\
\text { CMEM emission models }\end{array}$ & $\mathrm{CO}, \mathrm{NO}_{x}$ & $\begin{array}{l}\text { Emissions of considered pollutants are higher } \\
\text { for RBT than for SIG under both light and } \\
\text { congested traffic conditions. }\end{array}$ \\
\hline$[14]$ & Instrumented vehicle & $\mathrm{CO}, \mathrm{CO}_{2}, \mathrm{HC}, \mathrm{NO}_{x}$ & $\begin{array}{l}\text { Emissions for RBT are often higher than for } \\
\text { SIG and AWSC. Strong effect of driver behavior } \\
\text { on emissions. }\end{array}$ \\
\hline$[15]$ & INTEGRATION software & $\mathrm{CO}, \mathrm{CO}_{2}, \mathrm{HC}, \mathrm{NO}_{x}$ & $\begin{array}{c}\text { Emissions of CO, } \mathrm{HC} \text {, and } \mathrm{NO}_{x} \text { are generally } \\
\text { lower for RBT than for SIG and UNSIG; results } \\
\text { for } \mathrm{CO}_{2} \text { are dependent on overall demand and } \\
\text { turning ratios. }\end{array}$ \\
\hline$[16]$ & S-Paramics and AIRE software & $\mathrm{NO}_{x}, \mathrm{PM10}$, Total Carbon & $\begin{array}{l}\text { Emissions for RBT are slightly lower than for } \\
\text { SIG. }\end{array}$ \\
\hline$[17]$ & $\begin{array}{l}\text { Vehicle-specific power and } \\
\text { observed speed trajectories }\end{array}$ & $\mathrm{CO}, \mathrm{CO}_{2}, \mathrm{HC}, \mathrm{NO}_{x}$ & $\begin{array}{l}\text { Results of comparison of emissions for RBT } \\
\text { and SIG depend on demand-to-capacity ratio } \\
\text { and on quality of signal progression. }\end{array}$ \\
\hline$[18]$ & $\begin{array}{l}\text { VISSIM software; vehicle-specific } \\
\text { power and EMEP-EEA emissions } \\
\text { methodologies }\end{array}$ & $\mathrm{CO}, \mathrm{CO}_{2}, \mathrm{HC}, \mathrm{NO}_{x}, \mathrm{PM}$ & $\begin{array}{l}\text { For a sequence of intersections along an } \\
\text { arterial, emissions are lower for RBT than for } \\
\text { SIG and higher for RBT than for TWSC. }\end{array}$ \\
\hline
\end{tabular}

RBT: roundabout; SIG: signal-controlled intersection; UNSIG: unsignalized intersection; AWSC: all-way stop-controlled intersection; TWSC: two-way stopcontrolled intersection; EMEP-EEA: European Monitoring and Evaluation Programme-European Environment Agency.

TABLE 2: Signalized intersection characteristics [4].

\begin{tabular}{|c|c|c|c|c|c|c|c|c|c|}
\hline \multirow{2}{*}{\multicolumn{5}{|c|}{ Signal timing (North-South) }} & \multicolumn{5}{|c|}{ Approach characteristics } \\
\hline & & & & & & \multicolumn{4}{|c|}{ Approach } \\
\hline & Green & Amber & Red & Cycle & & North & East & South & West \\
\hline Minimum [s] & 49.0 & 3.0 & 31.8 & 85.8 & Entering lanes [\#] & 2 & 1 & 2 & 1 \\
\hline Median $[s]$ & 50.1 & 4.0 & 46.1 & 100.1 & Exiting lanes [\#] & 2 & 1 & 2 & 1 \\
\hline Maximum [s] & 54.9 & 4.9 & 62.1 & 116.2 & & & & & \\
\hline
\end{tabular}

from 7.00 to 10.30 and from 16.15 to 19.45 . Two drivers drove the test vehicle by alternating in one-hour sessions: a 30 -yearold man and a 58-year-old woman.

Information on geometric characteristics of the two intersection configurations (see Tables 2 and 3 ) were collected by field observations, and operational conditions were videorecorded during the experimental campaigns. Average thirtyminute total traffic flows for the signalized intersection and for the roundabout were, respectively, 1447 and 1409 in the morning peak period (7:30-9:00), 1255 and 1220 in the 
TABLE 3: Roundabout characteristics [4].

\begin{tabular}{|c|c|c|c|c|c|c|}
\hline \multirow[t]{3}{*}{ General characteristics } & & \multicolumn{5}{|c|}{ Approach characteristics } \\
\hline & & & \multicolumn{4}{|c|}{ Approach } \\
\hline & & & North & East & South & West \\
\hline Inscribed circle diameter $[\mathrm{m}]$ & 36 & Entering lanes $[\#]$ & 2 & 1 & 2 & 1 \\
\hline Central island diameter [m] & 20 & Exiting lanes [\#] & 1 & 1 & 1 & 1 \\
\hline Circulatory roadway width [m] & 8 & Splitter island width [m] & 4.50 & 3.80 & 4.20 & 4.20 \\
\hline Lanes in circulatory roadway [\#] & 1 & Entry width $[\mathrm{m}]$ & 7.25 & 4.50 & 7.25 & 3.75 \\
\hline
\end{tabular}

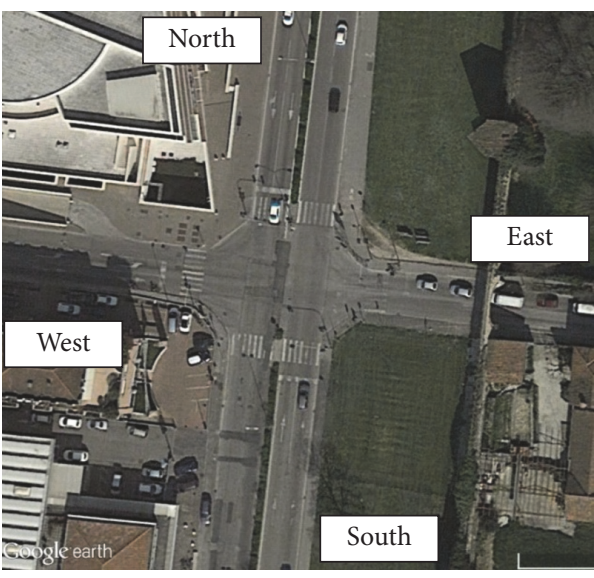

(a)

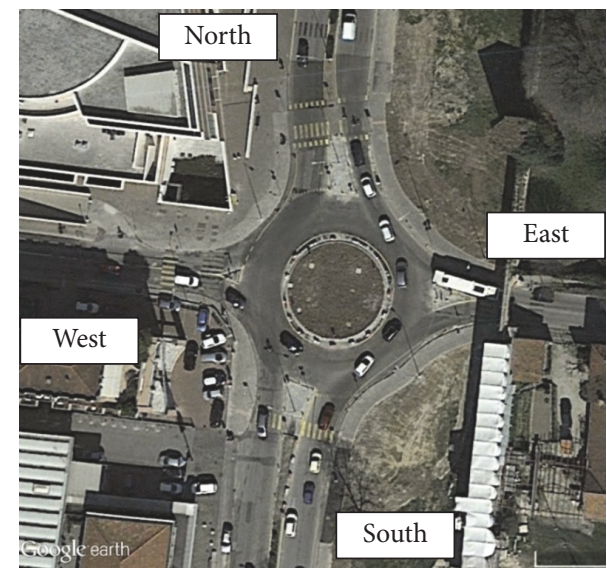

(b)

FIGURE 1: Aerial photograph of the study site: (a) signal-controlled intersection; (b) roundabout [4].

morning off-peak period (9:00-10:00), and 1302 and 1331 in the afternoon peak period (17:00-19:30). Since flow data did not show significant changes before and after the conversion of the intersection control, the comparative analysis was considered to be justified. Corresponding average temperature $\left({ }^{\circ} \mathrm{C}\right)$ observed for the signalized intersection and for the roundabout was 12.6 and 15.7 in the morning peak period, 16.9 and 20.5 in the morning off-peak period, and 21.3 and 25.7 in the afternoon peak period. All driving sessions took place in good weather conditions.

Data collected during the field tests were processed so as to obtain a proper time alignment of all signals acquired by the test vehicle (ECU, PEMS, and GPS data), which is essential for the calculation and verification of some test parameters as well as for the computation of pollutant emissions. GPS data were also processed to exclude anomalous and erroneous speed values. Following Rakha et al. [36], Robust Epanechnikov Kernel (EK) smoothing was applied in combination with an acceleration adjustment model.

To isolate the effect of the type of intersection control, vehicular emissions were measured over an influence area that included a $200 \mathrm{~m}$-long segment within the test itinerary, consisting of $150 \mathrm{~m}$ upstream the stop/yield line and $50 \mathrm{~m}$ downstream the stop/yield line. In order to assess possible effects of the trip direction, test runs were coded as "Trip A" when the vehicle traveled from North to South and "Trip B" when the vehicle traveled from South to North. The itinerary was chosen in such a way that the test vehicle trips could be considered to be representative of the traffic stream having the highest traffic volume for both the N-S and S-N directions.

For each trip, the final dataset includes the following information ( $1 \mathrm{~Hz}$ frequency):

(i) reference time;

(ii) vehicle position and speed, rpm, gear ratio, and engine load;

(iii) instantaneous $\mathrm{CO}_{2}(\mathrm{~g} / \mathrm{s}), \mathrm{CO}(\mathrm{mg} / \mathrm{s})$, and $\mathrm{NO}_{X}(\mathrm{mg} / \mathrm{s})$ emissions;

(iv) estimated fuel consumption $(\mathrm{g} / \mathrm{s})$;

(v) exhaust mass flow $(\mathrm{kg} / \mathrm{h})$.

As shown in Table 4, the dataset was further subdivided based on other factors, including time of day ("Morning", 7.30-10.00, versus "Afternoon", 17.00-19.30), traffic condition ("Peak", 7:30-9:00 and 17.00-19.30, versus "Off-peak", 9.00-10.00), and trip direction (“Trip A" versus “Trip B"). After aggregation of the instantaneous data, each trip was characterized by information such as speed profile, total travel time, and total emissions of each pollutant. A total of 396 trips were included in the final dataset.

\section{Results}

Statistical analyses on the data collected at the study site were carried out in order to assess the impact on emissions of replacing signal control with a roundabout. First, a general 
TABLE 4: Dataset of trips used for the analysis [4].

\begin{tabular}{|c|c|c|c|c|c|c|c|}
\hline \multirow{3}{*}{ Intersection } & \multicolumn{4}{|c|}{ Morning } & \multicolumn{2}{|c|}{ Afternoon } & \multirow{3}{*}{ Total } \\
\hline & \multicolumn{2}{|c|}{ Peak } & \multicolumn{2}{|c|}{ Off-peak } & \multicolumn{2}{|c|}{ Peak } & \\
\hline & Trip A & Trip B & Trip A & Trip B & Trip A & Trip B & \\
\hline Signalized & 32 & 33 & 25 & 24 & 43 & 45 & 202 \\
\hline Roundabout & 39 & 39 & 27 & 28 & 31 & 30 & 194 \\
\hline Total & 71 & 72 & 52 & 52 & 74 & 75 & 396 \\
\hline
\end{tabular}

TABLE 5: Descriptive statistics for $\mathrm{CO}_{2}, \mathrm{CO}$, and $\mathrm{NO}_{X}$ emissions by intersection control type.

\begin{tabular}{|c|c|c|c|}
\hline & $\begin{array}{l}\text { Signalized } \\
\text { intersection }\end{array}$ & Roundabout & Total \\
\hline Number of trips & 202 & 194 & 396 \\
\hline \multicolumn{4}{|l|}{$\mathrm{CO}_{2}(\mathrm{~g}):$} \\
\hline Mean & 59.62 & 51.75 & 55.76 \\
\hline SD & 19.45 & 18.91 & 19.56 \\
\hline Median & 59.88 & 45.46 & 53.05 \\
\hline$\left(\mathrm{Q}_{1}-\mathrm{Q}_{3}\right)$ & $(44.49-76.22)$ & $(38.53-60.33)$ & $(40.36-69.08)$ \\
\hline $\mathrm{CV} \%$ & 32.6 & 36.5 & 35.1 \\
\hline \multicolumn{4}{|l|}{$C O(\mathrm{mg}):$} \\
\hline Mean & 132.03 & 98.27 & 115.49 \\
\hline SD & 130.73 & 82.53 & 110.95 \\
\hline Median & 88.10 & 78.54 & 81.45 \\
\hline (Q1-Q3) & $(39.48-181.67)$ & $(37.30-133.49)$ & $(39.20-155.69)$ \\
\hline $\mathrm{CV} \%$ & 99.0 & 84.0 & 96.1 \\
\hline \multicolumn{4}{|l|}{$N O_{X}(\mathrm{mg}):$} \\
\hline Mean & 60.81 & 90.79 & 75.49 \\
\hline SD & 45.23 & 55.53 & 52.66 \\
\hline Median & 54.77 & 79.13 & 63.73 \\
\hline (Q1-Q3) & $(23.96-86.56)$ & $(46.98-127.64)$ & (35.94-107.35) \\
\hline CV\% & 74.4 & 61.2 & 69.8 \\
\hline
\end{tabular}

picture of the distributions of the observations before and after the conversion of intersection control was obtained using descriptive statistics computed for the entire set of trips and for six subsamples defined by time of day, traffic condition, and trip direction. Second, the statistical significance of the differences between traffic signal and roundabout controls in terms of both location and variability indexes of the respective sample distributions was tested. Third, focusing on trips carried out in peak traffic conditions (representing about $75 \%$ of the entire dataset), binary logistic regression models were developed in order to quantify the effects of the factors that significantly affect vehicular emissions and hence to estimate the probabilities of emission levels associated with different trip profiles, in particular with different forms of intersection control. All the above analyses, which are described separately in the following, were performed for each of the three pollutants under examination $\left(\mathrm{CO}_{2}, \mathrm{CO}\right.$, and $\left.\mathrm{NO}_{X}\right)$.

4.1. Empirical Distribution Functions of Pollutant Emissions and Related Statistics. Descriptive statistics based on the entire data sample are reported in Table 5 for the "before" (signal control) and "after" (roundabout) intersection configurations and for each of the considered pollutants. The total amount of a given pollutant emitted by the test vehicle during a single trip constitutes an elementary observation, and the complete sample consists of 396 such observations, almost evenly split among the two types of control (202 for signal and 194 for roundabout). The indicators used to characterize this sample are the following measures of central tendency and variability: mean value, median, standard deviation (SD), interquartile range $\left(Q_{1}-Q_{3}\right)$, and coefficient of variation $(\mathrm{CV})$. The values shown in Table 5 clearly suggest that emissions of $\mathrm{CO}_{2}$ and $\mathrm{CO}$ are higher, on average, for signal control than for roundabout, while the opposite is true for $\mathrm{NO}_{X}$ pollution. We note that these results are in agreement with the findings of [8], which is one of the few previous studies reporting analyses comparable to ours (before-andafter method based on field measurement of emissions using PEMS). The average level of dispersion relative to the mean, as expressed by the coefficient of variation, appears to be 


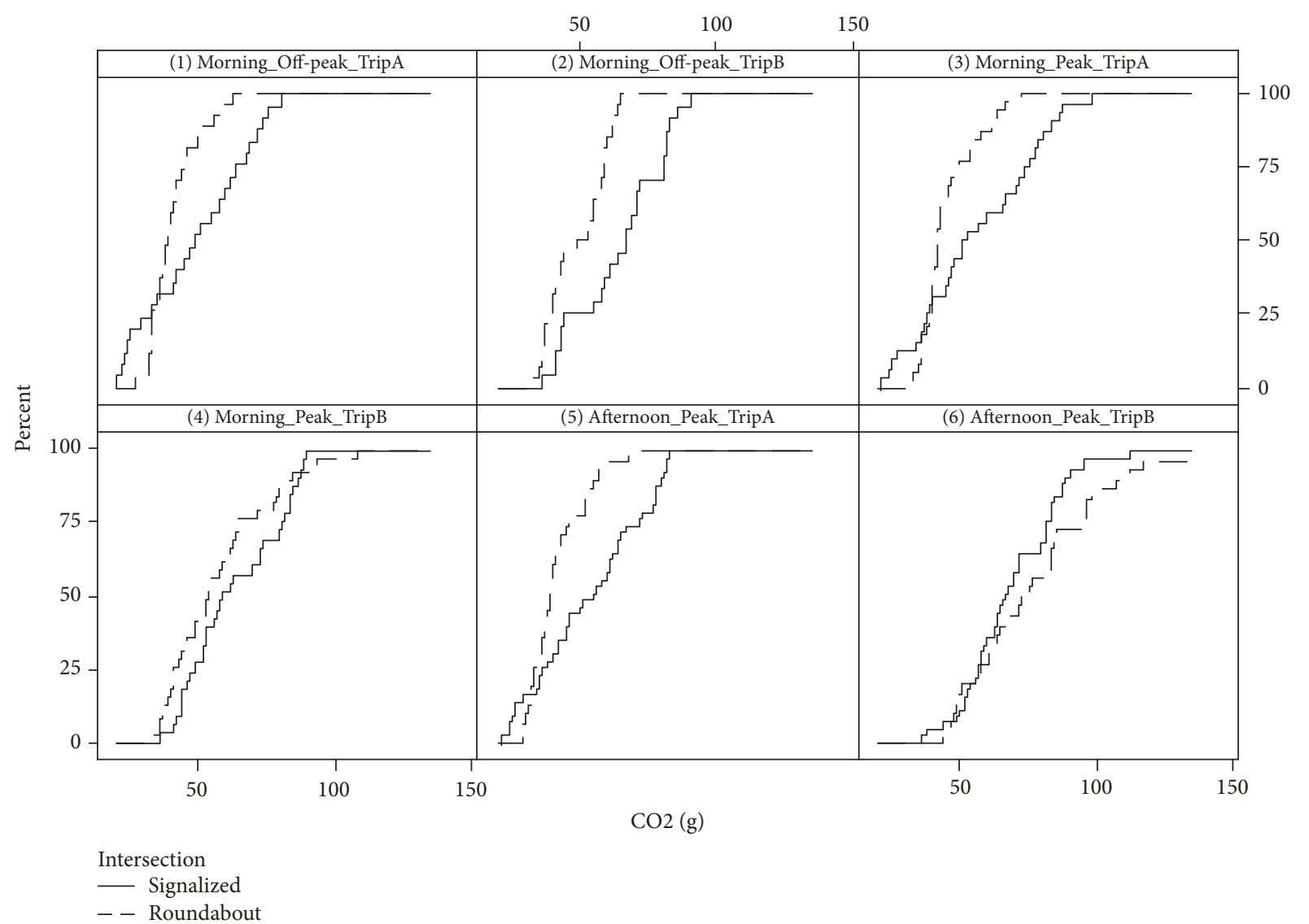

FIgURE 2: Empirical Cumulative Distribution Functions of $\mathrm{CO}_{2}$ emissions (g) by intersection type and trip conditions.

lower for the roundabout for two out of three pollutants. As previously mentioned, these differences have also been tested for statistical significance (see Section 4.2).

A more complete characterization of the relative environmental performance of the two intersection configurations is provided by Figures 2, 3, and 4, which show the empirical Cumulative Distribution Functions (CDFs) of each pollutant's emissions for traffic signal and roundabout and for six subsamples defined by time of day, traffic condition, and trip direction. Considering $\mathrm{NO}_{X}$ (Figure 4), it is seen that signal control appears to produce always lower emissions than the roundabout. This is consistent with the findings of previous work reported in the literature; see, for example, [8, 12-14]. Opposite results are obtained for $\mathrm{CO}_{2}$ (Figure 2), while for $\mathrm{CO}$ the roundabout is seen to be less polluting only in three out of six trip conditions (Figure 3 ).

4.2. Testing the Statistical Significance of the Effects of Control Type on Emissions. In order to determine whether the differences in pollutant emissions between the two types of intersection emerging from the preliminary analysis are statistically significant, we applied two-sample biaspect permutation tests [37-42]. In general, permutation tests are "distribution-free" statistical procedures that can be used to perform various types of analyses as an alternative to more conventional parametric tests. For example, a permutation test can be carried out in place of a Student's $t$-test to determine if two sample means are different at some specified significance level. In such a case, the permutation test would essentially consist of the following steps: (1) combine the data of the two samples; (2) generate at random a large number of different samples of the same sizes of the original ones; (3) calculate the differences of the means for each pair of generated samples; (4) count how often these differences are larger than the difference of the means of the original samples. The $p$ value can then be computed as the number of differences greater than the difference of the original samples divided by the total number of calculated differences.

In our specific application, we implemented a biaspect permutation test, which allows simultaneously taking into account differences in location and variability of the sample distribution. The location aspect is based on the comparison of location indexes, while the variability aspect is based on the comparison of second moments, and we applied a solution based on the nonparametric combination of dependent tests theory [38] within the permutation approach. In this framework, the global null hypothesis $\left(H_{0}\right)$ that the two groups (the two types of intersection control) have the same underlying distribution may be broken down into two partial null hypotheses, one related to the location aspect and the other related to the variability aspect. Therefore, we first applied two partial permutation tests, one for each partial null hypothesis, followed by their nonparametric combination. The latter makes use of a combining function based on the 


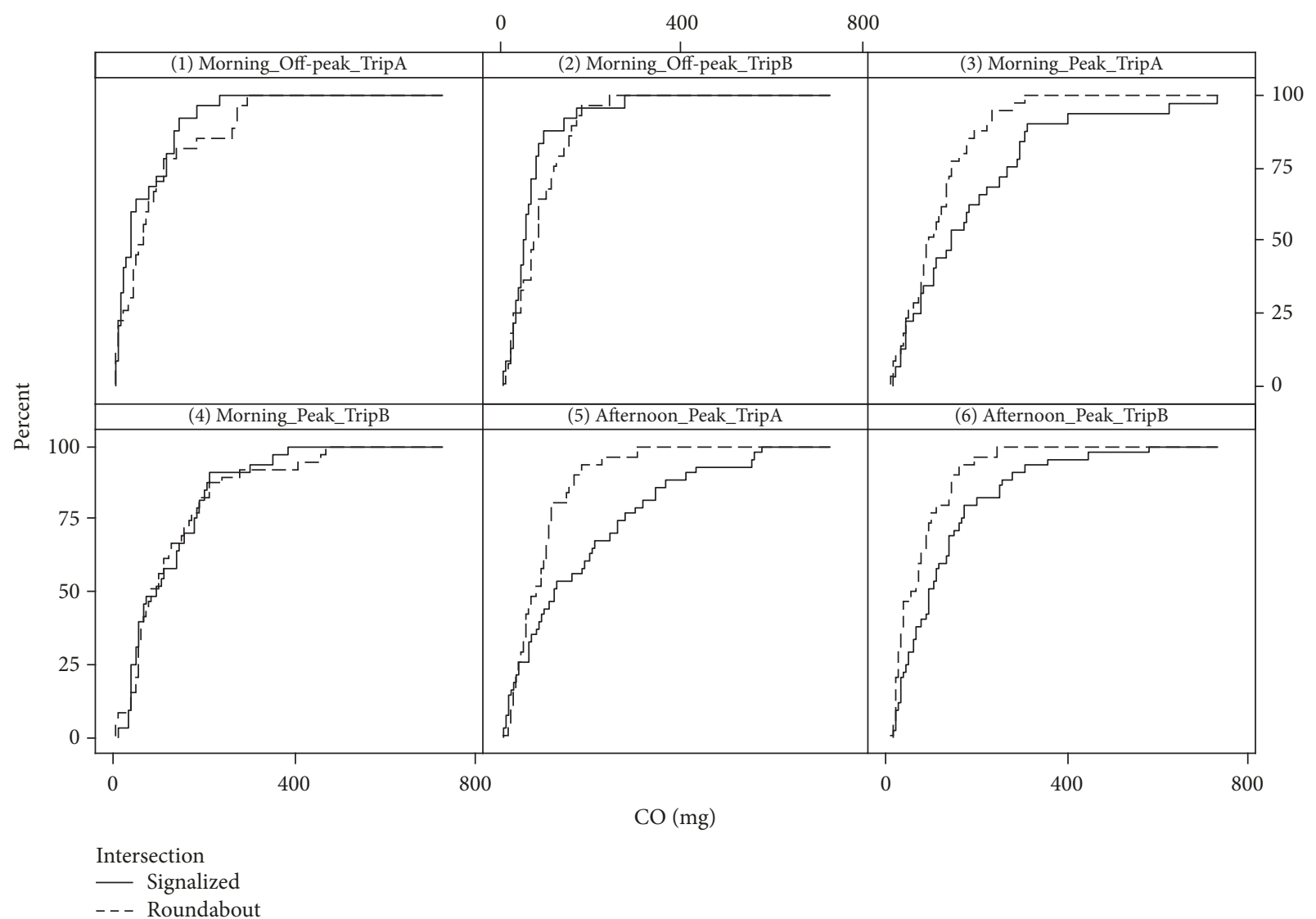

FIgure 3: Empirical Cumulative Distribution Functions of $\mathrm{CO}$ emissions (mg) by intersection type and trip conditions.

statistic $-2 \sum_{i} \log \left(\lambda_{i}\right)$, where $\lambda_{i}, i=1, \ldots, k$ are the $p$ values associated with the partial tests, and $k$ is the number of aspects being studied ( $k=2$ in our application). Permutation distributions of partial and combined tests are estimated using a Monte Carlo algorithm based on $B$ independent random permutations of the full dataset; here we used $B=$ 10000.

Hence, on the one hand, partial tests may provide marginal information for each specific aspect; on the other, they jointly provide information on the global hypothesis. Thus, if a significant departure from $H_{0}$ arises, we can explore the nature of this departure in more detail. Two-sided alternatives with a significance level $\alpha=0.05$ were considered for all the tests. Bonferroni-Holm's procedure for multiple testing was used in order to keep under control the familywise Type I error [38].

The overall adjusted $p$ values presented in Table 7 indicate that differences in emissions between the two types of control are significant at the $5 \%$ level in 10 out of the 18 trip profiles obtained by combining time of day (Morning or Afternoon), traffic conditions (Peak or Off-peak), and trip direction (A or B). For three of the remaining 8 trip profiles the $p$ values lie between $5 \%$ and $10 \%$. The separate tests for location and variability give similar results in terms of significance/nonsignificance of the differences. If we restrict our attention to the overall adjusted $p$ values that are below the $5 \%$ threshold, results are clear-cut: $\mathrm{CO}_{2}$ and $\mathrm{CO}$ are lower for the roundabout than for the signalized intersection, while the opposite is true for $\mathrm{NO}_{X}$ emissions. Similar conclusions can be reached if we focus on the cases in which differences are significant at a level between $5 \%$ and $10 \%$.

An explanation of these results may be provided by the distribution of total trip time among the four typical driving modes (idle, acceleration, deceleration, and cruise), which, as shown in Table 6, appears to be quite different for the two types of intersection. For example, emissions of $\mathrm{NO}_{X}$ are known to be very low during the idle mode, which represents a negligible fraction of time for the roundabout but not for the signal-controlled intersection.

4.3. Logistic Regression Models. In order to evaluate possible associations between emission levels, intersection control type, and other significant explanatory variables, we developed a binary logistic regression model for each of the three pollutants considered in the study. Logistic regression is a statistical technique that can be especially useful when trying to identify the existence (and quantify the strength) of relationships involving a categorical response variable. In this analysis, only trips occurring during peak traffic conditions (292 observations, approximately equal to $75 \%$ of the entire sample) were considered. This choice is consistent with the idea of incorporating the assessment of the environmental impact of intersections into the process of their operational 
TABLE 6: Driving mode definition and distribution of trip time among modes for signal and roundabout.

\begin{tabular}{|c|c|c|c|c|}
\hline \multirow{2}{*}{ Driving mode } & \multirow{2}{*}{ Speed $[\mathrm{Km} / \mathrm{h}]$} & \multirow{2}{*}{ Acceleration $[\mathrm{Km} / \mathrm{h} / \mathrm{s}]$} & \multicolumn{2}{|c|}{ Time in mode [\%] } \\
\hline & & & SIG & RBT \\
\hline Idle & $<0.1$ & $<0.1$ and $>-0.1$ & 12.59 & 0.86 \\
\hline Acceleration & $>0.1$ & $>0.36$ & 34.14 & 39.93 \\
\hline Deceleration & $>0.1$ & $<-0.36$ & 25.80 & 41.97 \\
\hline Cruise & \multicolumn{2}{|c|}{ all other cases } & 27.47 & 17.24 \\
\hline
\end{tabular}

Note. SIG: signal control; RBT: roundabout.

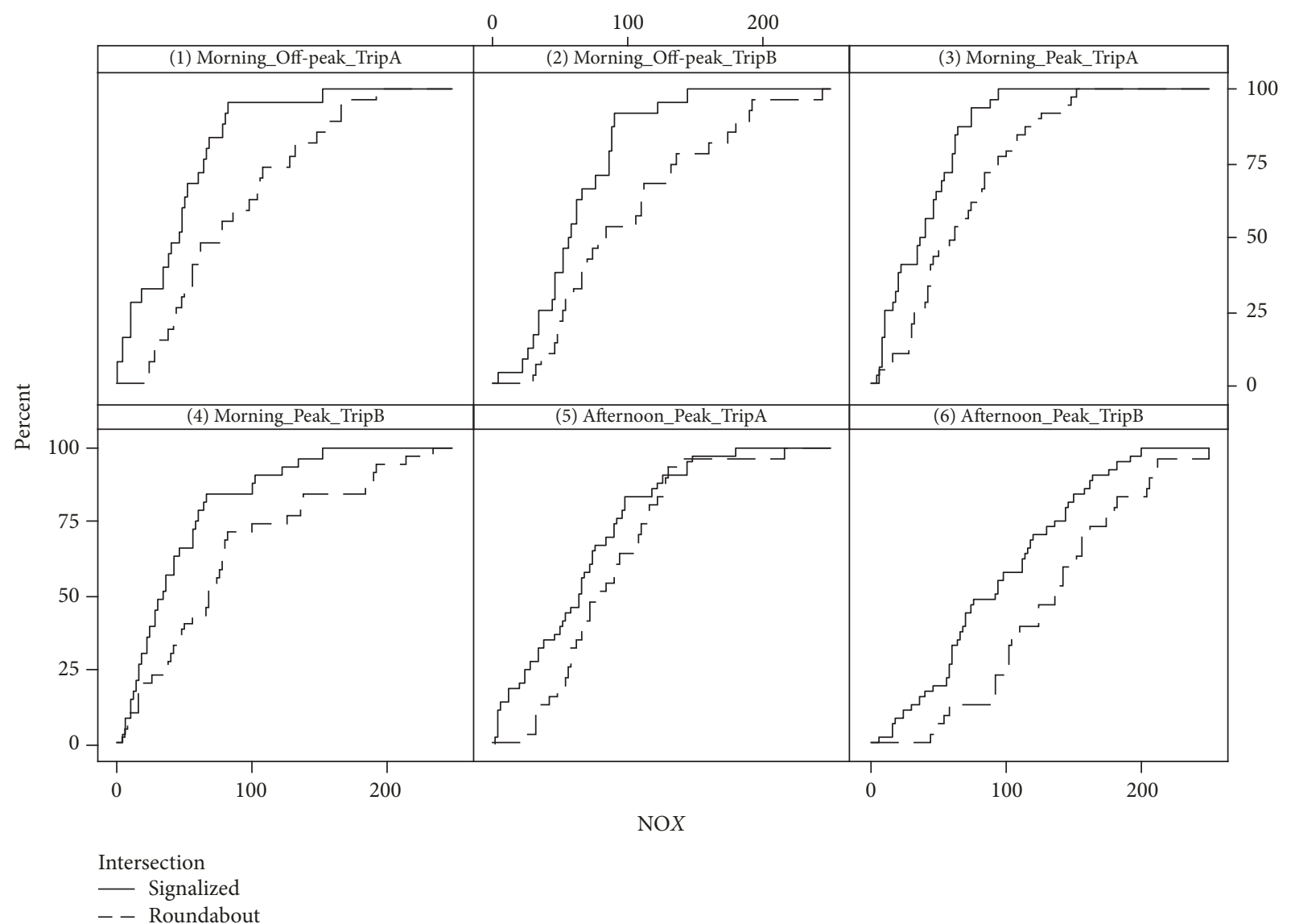

Figure 4: Empirical Cumulative Distribution Functions of $\mathrm{NO}_{X}$ emissions (mg) by intersection type and trip conditions.

analysis (or design), for which peak traffic volumes are commonly considered. A binary response variable was obtained by classifying each trip into one of two mutually exclusive categories, based on whether or not the emissions of the given pollutant exceeded the respective mean value computed over all 292 trips.

The general form of the logistic regression model is

$$
\ln \left(\frac{\pi}{1-\pi}\right)=\beta_{0}+\beta_{1} X_{1}+\cdots+\beta_{K} X_{K}
$$

where $\pi$ represents the probability that emissions of the given pollutant exceed the corresponding mean value, $X_{1}, \ldots, X_{K}$ are the explanatory variables, and $\beta_{0}, \beta_{1}, \ldots, \beta_{K}$ are the model coefficients. As will be seen below, in our models all the explanatory variables are of the categorical type. Numerical values of the coefficients were determined through Maximum
Likelihood Estimation. The three logistic regression models, which include only predictors that showed significant effects on emissions, are presented and discussed separately in the next subsections.

For each model, the following information is provided in table format: the coefficient $\beta$ associated with each predictor, the corresponding odds ratio (equal to $\exp (\beta)$ ) with the respective 95\% Confidence Interval and $p$ value, and the Likelihood Ratio Chi-square test with the corresponding $p$ value. The latter is a test of the null hypothesis that all model coefficients (except $\beta_{0}$ ) are simultaneously zero versus the alternative hypothesis that at least one of the coefficients is different from zero; therefore, it is a test of the joint significance of all the predictors included in the model. In addition, the results of each model are further illustrated by means of risk charts, which display, for each combination 


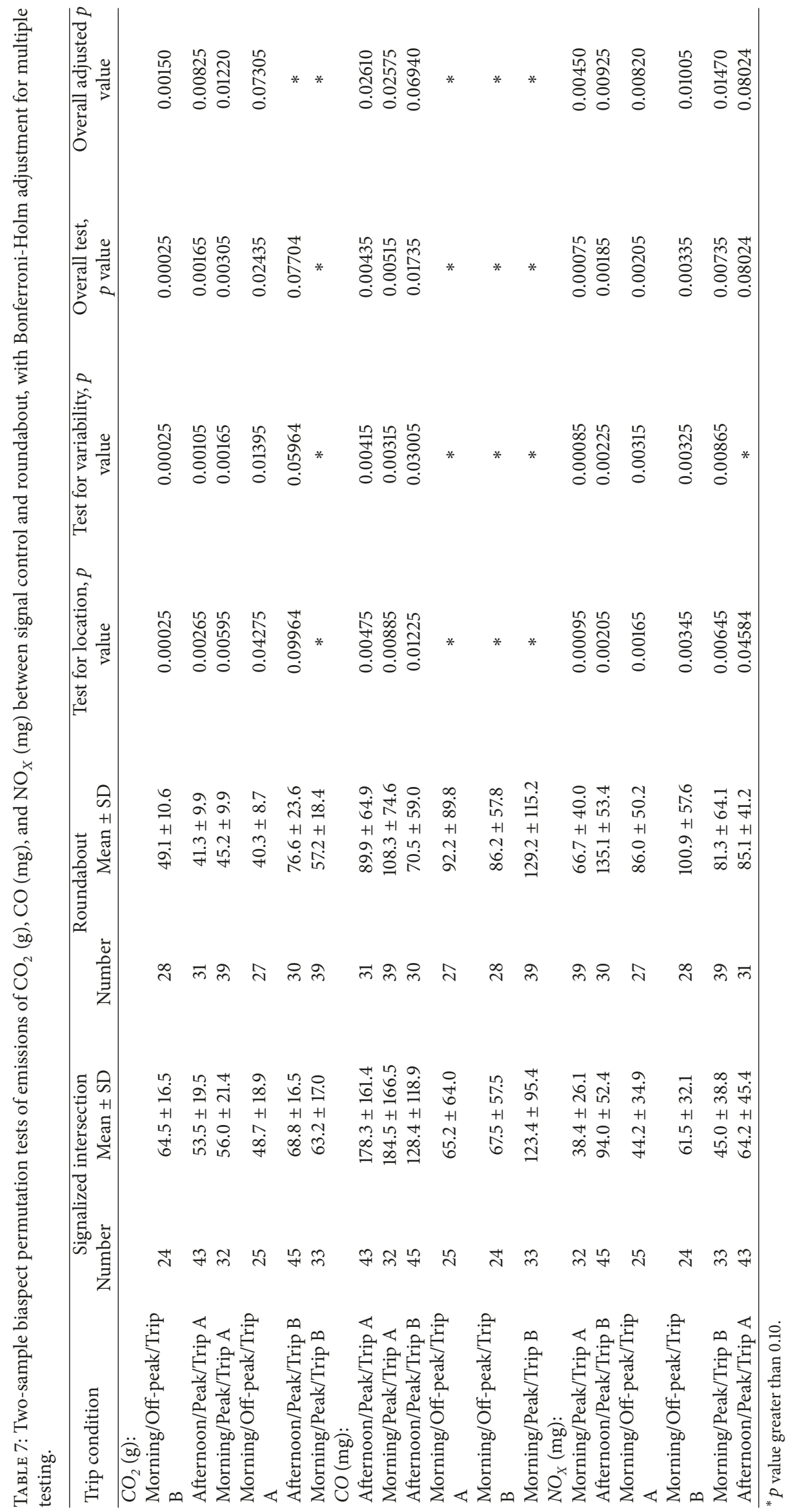


TABLE 8: Descriptive statistics for $\mathrm{CO}_{2}$ emissions (g) by intersection type (traffic condition = peak).

\begin{tabular}{lcccccc}
\hline Intersection & Number of trips & Mean & SD & Median & $\left(\mathrm{Q}_{1}-\mathrm{Q}_{3}\right)$ & $\mathrm{CV}$ \\
\hline Signalized & 153 & 60.63 & 19.44 & 60.43 & $(45.42-78.21)$ & 32.1 \\
Roundabout & 139 & 54.49 & 20.72 & 48.14 & $(39.75-63.79)$ & 38.0 \\
\hline Total & 292 & 57.70 & 20.26 & 53.98 & $(41.18-72.12)$ & 35.1 \\
\hline
\end{tabular}

TABLE 9: Logistic regression relating risk of "high" $\mathrm{CO}_{2}$ emissions to intersection type and trip direction.

\begin{tabular}{|c|c|c|c|c|c|c|}
\hline & Number of trips with $\mathrm{CO}_{2} \geq 58 \mathrm{~g}$ & Number of total trips & Coefficient & Odds ratio & $95 \% \mathrm{CI}$ & $p$ value \\
\hline \multicolumn{7}{|l|}{ Intersection: } \\
\hline Roundabout & 45 & 139 & & 1 & & \\
\hline Signalized & 82 & 153 & 0.958 & 2.61 & $(1.57,4.32)$ & 0.0002 \\
\hline \multicolumn{7}{|l|}{ Trip direction: } \\
\hline Trip A & 41 & 145 & & 1 & & \\
\hline Trip B & 86 & 147 & 1.331 & 3.78 & $(2.28,6.27)$ & $<0.0001$ \\
\hline
\end{tabular}

(Likelihood ratio: $\chi^{2}=41.96, \mathrm{DF}=2, p$ value $<0.0001$ ).

of values of the predictors (called a profile), the probability (expressed as a percentage) that a trip characterized by that profile will produce emissions of the given pollutant greater than the respective mean value.

\subsubsection{Binary Logistic Regression Model for $\mathrm{CO}_{2}$ Emissions.} Basic statistics describing the emissions of $\mathrm{CO}_{2}$ for the sample of trips carried out in peak traffic conditions are presented in Table 8 . The values of mean, median, standard deviation, interquartile range, and coefficient of variation are shown separately for the "before" (signalized intersection) and "after" (roundabout) conditions. Emissions produced under roundabout control are seen to be lower on average but slightly more dispersed as compared to those produced under signal control operation.

Using binary logistic regression with $\mathrm{CO}_{2}$ emissions as the response variable, we identified intersection type and trip direction as statistically significant predictors. A cutoff value equal to the mean ( $58 \mathrm{~g}$ per trip) was assumed in order to categorize the response into "low" and "high" emissions of the pollutant under consideration. The results reported in Table 9 support both the overall significance of the model (based on the likelihood ratio test) and the individual significance of each of the two explanatory variables. The values of the odds ratio suggest that emissions of $\mathrm{CO}_{2}$ per trip are about 2.6 times as likely to exceed $58 \mathrm{~g}$ under signal control than with the roundabout, and about 3.8 times as likely to exceed the above threshold for direction $\mathrm{B}$ than for direction $\mathrm{A}$. Therefore, trip direction is seen to be a very influential predictor of $\mathrm{CO}_{2}$ emissions in this case.

We hypothesize that this effect, which is specific to the study site under consideration, is mainly attributable to unbalanced traffic volumes and, for the roundabout, also to differences in geometric and functional characteristics between the two directions (see Figure 1). In particular, the deflection of the vehicular trajectories appears to be more pronounced for the northbound direction (corresponding to "Trip B") than for the opposite one, causing sharper deceleration and acceleration in nonqueuing conditions. A

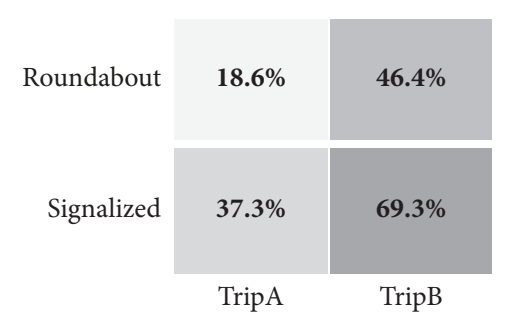

Figure 5: Probabilities of $\mathrm{CO}_{2}(\mathrm{~g}) \geq 58 \mathrm{~g}$ (traffic condition = peak).

further hindrance to northbound traffic is due to the width of the roundabout exit, which is narrower on the North leg as compared to the South leg. In addition, pedestrian flows on the North crosswalk were observed to cause significant impedance to vehicles exiting the roundabout in the northbound direction, while this effect was not detected for southbound vehicles because of considerably lower pedestrian volumes on the South crosswalk. The interaction between vehicular streams and crossing pedestrians at roundabouts is a factor which may substantially affect intersection operations, as shown by previous studies on the related issue of roundabout capacity reduction in the presence of significant levels of pedestrian activity $[43,44]$.

Similar conclusions about the effects of the two predictors are suggested by the risk chart displayed in Figure 5, which represents the probability of emissions exceeding $58 \mathrm{~g}$ per trip associated with each profile of explanatory variables. Profiles with the lowest and the highest risk are, respectively, those corresponding to the roundabout in direction $\mathrm{A}$ and the signalized intersection in direction $\mathrm{B}$.

4.3.2. Binary Logistic Regression Model for CO Emissions. Basic statistics describing the emissions of $\mathrm{CO}$ for the sample of trips carried out in peak traffic conditions are presented in Table 10, indicating that vehicular emissions generated under roundabout control are lower on average and are characterized by less variability in comparison to signal 
TABLE 10: Descriptive statistics for CO emissions (mg) by intersection type (traffic condition = peak).

\begin{tabular}{lcccccc}
\hline Intersection & Number of trips & Mean & SD & Median & $\left(Q_{1}-Q_{3}\right)$ & CV\% \\
\hline Signalized & 153 & 153.10 & 140.10 & 106.30 & $(46.80-208.00)$ & 91.5 \\
Roundabout & 139 & 101.89 & 85.46 & 81.09 & $(39.24-137.86)$ & 83.9 \\
\hline Total & 292 & 128.70 & 119.86 & 92.18 & $(42.06-174.65)$ \\
\hline
\end{tabular}

TABLE 11: Logistic regression relating risk of "high" CO emissions to intersection type and test car driver.

\begin{tabular}{|c|c|c|c|c|c|c|}
\hline & Number of trips with $\mathrm{CO} \geq 129 \mathrm{mg}$ & Number of total trips & Coefficient & Odds ratio & $95 \% \mathrm{CI}$ & $p$ value \\
\hline \multicolumn{7}{|l|}{ Intersection: } \\
\hline Roundabout & 38 & 139 & & 1 & & \\
\hline Signalized & 70 & 153 & 0.662 & 1.94 & $(1.16,3.24)$ & 0.0114 \\
\hline \multicolumn{7}{|l|}{ Driver: } \\
\hline D2 & 19 & 108 & & 1 & & \\
\hline D1 & 89 & 184 & 1.398 & 4.05 & $(2.27,7.23)$ & $<0.0001$ \\
\hline
\end{tabular}

(Likelihood ratio: $\chi^{2}=35.92, \mathrm{DF}=2, p$ value $\left.<0.0001\right)$.

TABLE 12: Descriptive statistics for $\mathrm{NO}_{X}$ emissions (mg) by intersection type (traffic condition = peak).

\begin{tabular}{|c|c|c|c|c|c|c|}
\hline Intersection & Number of trips & Mean & SD & Median & $\left(Q_{1}-Q_{3}\right)$ & $\mathrm{CV} \%$ \\
\hline Signalized & 153 & 63.42 & 48.01 & 58.22 & $(23.14-93.01)$ & 75.7 \\
\hline Roundabout & 139 & 89.67 & 56.23 & 79.69 & $(44.26-125.86)$ & 62.7 \\
\hline Total & 292 & 75.92 & 53.62 & 65.47 & $(34.13-109.97)$ & 70.6 \\
\hline
\end{tabular}

control. In the case of binary logistic regression with $\mathrm{CO}$ emissions as the response variable, the statistically significant predictors were found to be intersection type and test car driver (see Table 11). The two drivers who took turns during the experiment are designated as D1 (a 30-year-old man) and D2 (a 58-year-old woman). The cutoff value used to categorize the response into "low" and "high" emissions of CO is equal to $129 \mathrm{mg}$ per trip.

Also in this case the likelihood ratio test and the $p$ values associated with the two explanatory variables suggest the statistical significance of the estimated model, and the values of the odds ratio indicate that driving behavior represents the dominant factor in determining CO pollution, with driver D1 being four times as likely to generate emissions above $129 \mathrm{mg}$ per trip than driver D2. In general, it is well known that higher emissions are associated with more aggressive driving styles characterized by sharp acceleration and deceleration. The results shown in Table 11 are confirmed by the risk chart displayed in Figure 6, which shows that the probability of CO emissions exceeding $129 \mathrm{mg}$ per trip is lowest for driver D2 in the presence of the roundabout and highest for driver D1 in the presence of signal control.

4.3.3. Binary Logistic Regression Model for $N_{X}$ Emissions. Table 12 shows the chosen descriptive statistics for $\mathrm{NO}_{X}$ emissions by intersection type for the sample of trips carried out in peak traffic conditions. Opposite to the results obtained for the two previously considered pollutants, emissions of $\mathrm{NO}_{X}$ appear to be lower on average under signal control than with the roundabout. Instead, the level of dispersion of the observations relative to the mean (as measured by $\mathrm{CV}$ ) is seen to be higher for the signal-controlled intersection. Turning

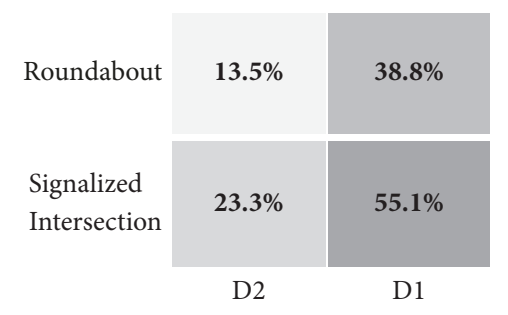

FIgURE 6: Probabilities of CO $(\mathrm{mg}) \geq 129 \mathrm{mg}$ (traffic condition $=$ peak).

then to binary logistic regression with $\mathrm{NO}_{X}$ emissions as the response variable, the statistically significant predictors were found to be intersection type, trip direction, and test car driver (see Table 13). The cutoff value used to categorize the response into "low" and "high" emissions of $\mathrm{NO}_{X}$ is equal to $76 \mathrm{mg}$ per trip.

Also in this case the likelihood ratio test and the $p$ values associated with the three explanatory variables suggest the statistical significance of the estimated model, and the values of the odds ratio indicate that driving behavior represents the most influential factor in determining $\mathrm{NO}_{X}$ pollution. Note, however, that in this case the odds ratio of the "driver" predictor appears to be reversed as compared to the model of $\mathrm{CO}$ emissions, in the sense that driver D2 is now more likely to produce emissions of $\mathrm{NO}_{X}$ above the mean as compared to $\mathrm{D}$; this is an interesting result deserving further investigation as suggested in the conclusions section. In addition, if we compare these results with those of the $\mathrm{CO}_{2}$ model, it is interesting to observe that the introduction of the "driver" predictor tends to "mitigate" the effect of trip direction, which 
TABLE 13: Logistic regression relating risk of "high" $\mathrm{NO}_{X}$ emissions to intersection type, trip direction, and test car driver.

\begin{tabular}{|c|c|c|c|c|c|c|}
\hline & Number of trips with $\mathrm{NO}_{X} \geq 76 \mathrm{mg}$ & Number of total trips & Coefficient & Odds ratio & $95 \% \mathrm{CI}$ & $p$ value \\
\hline \multicolumn{7}{|l|}{ Intersection: } \\
\hline Signalized & 46 & 153 & & 1 & & \\
\hline Roundabout & 74 & 139 & 0.883 & 2.42 & $(1.44,4.05)$ & 0.0008 \\
\hline \multicolumn{7}{|l|}{ Trip direction: } \\
\hline Trip A & 48 & 145 & & 1 & & \\
\hline Trip $B$ & 72 & 147 & 0.831 & 2.30 & $(1.36,3.87)$ & 0.0019 \\
\hline \multicolumn{7}{|l|}{ Driver: } \\
\hline D1 & 52 & 184 & & 1 & & \\
\hline D2 & 68 & 108 & 1.447 & 4.25 & $(2.50,7.23)$ & $<0.0001$ \\
\hline
\end{tabular}

TABLE 14: Probabilities of $\mathrm{NO}_{X}(\mathrm{mg}) \geq 76 \mathrm{mg}$ (traffic condition = peak).

\begin{tabular}{lccc}
\hline Probability of $\mathrm{NO}_{X}(\mathrm{mg}) \geq 76 \mathrm{mg}$ & Intersection & Driver & Trip direction \\
\hline $14.2 \%$ & Signalized & D1 & A \\
$27.6 \%$ & Signalized & D1 & B \\
$28.7 \%$ & Roundabout & D1 & A \\
$41.4 \%$ & Signalized & D2 & A \\
$48.0 \%$ & Roundabout & D1 & B \\
$61.8 \%$ & Signalized & D2 & B \\
$63.1 \%$ & Roundabout & D2 & A \\
$79.7 \%$ & Roundabout & D2 & B \\
\hline
\end{tabular}

is now similar (in terms of coefficient value and odds ratio) to the effect of the type of control. Finally, the risk chart displayed in Table 14 shows the probability of $\mathrm{NO}_{X}$ emissions exceeding $76 \mathrm{mg}$ per trip for the eight profiles included in the model. It can be seen, in particular, that such probability is lowest for driver D1 and trip direction A under signal control, and highest for driver D2 and trip direction B in the presence of the roundabout.

\section{Conclusions}

A comparative analysis of vehicular emissions at a road intersection under different types of control has been described in this paper. The study has adopted a before-and-after approach based on field measurements of three major pollutants $\left(\mathrm{CO}_{2}\right.$, $\mathrm{CO}$, and $\left.\mathrm{NO}_{X}\right)$ at a site where a roundabout has replaced signal control. Two data collection campaigns were conducted by means of an instrumented car at an interval of one year under similar traffic volumes and atmospheric conditions. It is believed that the experimental evidence provided by this study may contribute significantly to the understanding of the relationship between road traffic emissions and type of intersection operations.

The existence of statistically significant differences between emissions produced by the test vehicle in the "before" and "after" intersection configurations has been assessed using two-sample biaspect permutation tests, a method that can provide more robust evidence as compared to traditional parametric tests, as it allows simultaneously detecting differences in location and variability characteristics of the distributions of the observations in the situations being compared.
Relationships between emission levels, intersection control type, and other significant explanatory variables have then been identified using logistic regression models separately for each of the three pollutants under consideration.

Our results are clear-cut: the above analyses show that vehicular emissions of $\mathrm{CO}_{2}$ and $\mathrm{CO}$ are generally lower for the roundabout than for the signal-controlled intersection, while an opposite finding emerges for $\mathrm{NO}_{X}$ emissions. We also found that trip direction (reflecting specific geometric, functional, and traffic characteristics of the study site) and driver behavior have a considerable impact on the emissions of all three pollutants.

A comparison of these findings with the results reported in the existing literature is not straightforward, mainly because most of the previous studies on the subject are based on a modeling/simulation approach rather than on direct field measurements. Despite these difficulties in establishing meaningful comparisons, we note that our results are in agreement with at least some of the previous works found in the literature.

It is believed that results obtained in field studies such as the one described in this paper may be very useful for the calibration and validation of microscopic models relating pollutant emissions to vehicular traffic conditions. These models, in turn, can become very effective tools in the context of procedures for the environmental impact assessment of road projects.

The complexity of the problem under consideration suggests that further research is needed. A possible future development of the study described in this paper is a detailed analysis of the effect on emissions of the composition of 
trips in terms of vehicle operating modes (idle, acceleration, cruise, and deceleration) in relation to the type of intersection control.

Another issue that could be explored in future work is the effect on emissions of driving style, for which we plan to design and implement a controlled experiment using a driving simulator. This will allow testing the behavior of a considerable number of subjects, which is an essential condition to support the validity and statistical significance of the results. In the study described in this paper, only two drivers were involved, and this did not allow exploring the full range of behaviors that one can expect to find in the real world.

Since the signal-controlled intersection considered in this study did not necessarily operate with optimal timing parameters, further research could also be devoted to comparing pollutant emissions produced by vehicles under an optimized traffic signal plan and under roundabout intersection control. A microsimulation approach appears to be particularly suitable to investigate this issue.

Another aspect deserving consideration and analysis in future developments of this study is the fact that geometric layout (e.g., number of approach lanes) of the intersection is generally modified when switching from signal control to roundabout, with possible significant impacts on pollutant emissions. Moreover, the research described in this paper could be extended by considering emissions produced by light and heavy goods' vehicles, in consideration of the growing importance of environmental aspects in the context of urban freight delivery systems $[45,46]$.

Finally, with specific reference to the roundabout, it would be interesting to assess the impact on emissions of conflicting pedestrian flows on intersection crosswalks. This would require a new campaign of data collection, in which pedestrian flows should be measured during the intervals in which the test vehicle crosses the roundabout. Such data on pedestrian volumes could then be included in the logistic regression models as an additional explanatory variable and tested for statistical significance.

\section{Conflicts of Interest}

The authors declare that there are no conflicts of interest regarding the publication of this article.

\section{Acknowledgments}

This work was supported by the University of Padova [Grant no. CPDA 128393/12].

\section{References}

[1] A. Matzoros and D. Van Vliet, "A model of air pollution from road traffic, based on the characteristics of interrupted flow and junction control: Part I - model description," Transportation Research Part A: Policy and Practice, vol. 26, no. 4, pp. 315-330, 1992.

[2] S. Pandian, S. Gokhale, and A. K. Ghoshal, "Evaluating effects of traffic and vehicle characteristics on vehicular emissions near traffic intersections," Transportation Research Part D: Transport and Environment, vol. 14, no. 3, pp. 180-196, 2009.

[3] Federal Highway Administration, 2010. Roundabouts: Technical Summary. FHWA-SA-10-006. U.S. Department of Transportation.

[4] C. Meneguzzer, M. Gastaldi, R. Rossi, G. Gecchele, and M. V. Prati, "Comparison of exhaust emissions at intersections under traffic signal versus roundabout control using an instrumented vehicle," Transportation Research Procedia, vol. 25, pp. 15971609, 2017.

[5] M. Gastaldi, C. Meneguzzer, R. A. Giancristofaro, G. Gecchele, L. D. Lucia, and M. V. Prati, "On-road measurement of $\mathrm{CO}_{2}$ vehicle emissions under alternative forms of intersection control," Transportation Research Procedia, vol. 27, pp. 476-483, 2017.

[6] C. Hydén and A. Várhelyi, "The effects on safety, time consumption and environment of large scale use of roundabouts in an urban area: A case study," Accident Analysis \& Prevention, vol. 32, no. 1, pp. 11-23, 2000.

[7] A. Várhelyi, "The effects of small roundabouts on emissions and fuel consumption: A case study," Transportation Research Part D: Transport and Environment, vol. 7, no. 1, pp. 65-71, 2002.

[8] P. Zuger, A. Porchet, and D. Burch, "Roundabouts, fuel consumption, emissions of pollutants, crossing times," in Proceedings of the First Swiss Transport Research Conference, Ascona, Switzerland, 2001.

[9] S. Mandavilli, M. J. Rys, and E. R. Russell, "Environmental impact of modern roundabouts," International Journal of Industrial Ergonomics, vol. 38, no. 2, pp. 135-142, 2008.

[10] E. Vlahos, A. Polus, D. Lacombe, P. Ranjitkar, A. Faghri, and B. R. Fortunato III, "Evaluating the conversion of all-way stop-controlled intersections into roundabouts," Transportation Research Record, no. 2078, pp. 80-89, 2008.

[11] Z. Yang, Y. Zhang, R. Zhu, and Y. Zhang, "Multiobjective Evaluation in Countermeasure Selection at Two-Way StopControlled Intersections," Transportation Research Record, vol. 2635, pp. 36-45, 2017.

[12] K. Ahn, N. Kronprasert, and H. Rakha, "Energy and environmental assessment of high-speed roundabouts," Transportation Research Record, no. 2123, pp. 54-65, 2009.

[13] R. Chamberlin, B. Swanson, E. Talbot, J. Dumont, and S. Pesci, "Analysis of MOVES and CMEM for evaluating the emissions impacts of an intersection control change," in Proceedings of the 90th Annual Meeting of the Transportation Research Board, Washington, DC, USA, 2011.

[14] S. L. Hallmark, B. Wang, A. Mudgal, and H. Isebrands, "Onroad evaluation of emission impacts of roundabouts," Transportation Research Record, no. 2265, pp. 226-233, 2011.

[15] M. Jackson and H. A. Rakha, "Are roundabouts environmentally friendly? An evaluation for uniform approach demands," in Proceedings of the 91st Annual Meeting of the Transportation Research Board, Washington, DC, USA, 2012.

[16] M. Gastaldi, C. Meneguzzer, R. Rossi, L. Della Lucia, and G. Gecchele, "Evaluation of air pollution impacts of a signal control to roundabout conversion using microsimulation," Transp. Res. Procedia, vol. 3, pp. 1031-1040, 2014.

[17] K. Salamati, N. M. Rouphail, H. C. Frey, B. Liu, and B. J. Schroeder, "Simplified method for comparing emissions in roundabouts and at signalized intersections," Transportation Research Record, vol. 2517, pp. 48-60, 2015. 
[18] P. Fernandes, T. Fontes, M. Neves et al., "Assessment of corridors with different types of intersections: Environmental and traffic performance analysis," Transportation Research Record, vol. 2503, pp. 39-50, 2015.

[19] A. Unal, N. Rouphail, and H. Frey, "Effect of Arterial Signalization and Level of Service on Measured Vehicle Emissions," Transportation Research Record, vol. 1842, pp. 47-56, 2003.

[20] F. Tao, Q. Shi, and L. Yu, "Evaluation of effectiveness of coordinated signal control in reducing vehicle emissions during peak hours versus nonpeak hours," Transportation Research Record, no. 2233, pp. 45-52, 2011.

[21] S. Mamarikas, I. Stamos, J. M. Salanova Grau, E. Mitsakis, and G. Aifadopoulou, "The contribution of traffic signals adjustment and coordination in mitigating $\mathrm{CO}_{2}$ emissions at urban arterials," in Proceedings of the 96th Annual Meeting of the Transportation Research Board, Washington, D.C, USA, 2017.

[22] M. Halkias, T. Leng, M. Sorell, J. Parks, and A. Skabardonis, "Arterial speed management with control measures: the case of San Francisco," in Proceedings of the 96th Annual Meeting of the Transportation Research Board, Washington, DC, USA, 2017.

[23] M. C. Coelho, T. L. Farias, and N. M. Rouphail, "Effect of roundabout operations on pollutant emissions," Transportation Research Part D: Transport and Environment, vol. 11, no. 5, pp. 333-343, 2006.

[24] K. Salamati, M. Coelho, P. Fernandes, N. Rouphail, H. Frey, and J. Bandeira, "Emissions estimation at multilane roundabouts," Transportation Research Record, no. 2389, pp. 12-21, 2013.

[25] A. Mudgal, S. Hallmark, A. Carriquiry, and K. Gkritza, "Driving behavior at a roundabout: A hierarchical Bayesian regression analysis," Transportation Research Part D: Transport and Environment, vol. 26, pp. 20-26, 2014.

[26] A. Papson, S. Hartley, and K.-L. Kuo, "Analysis of emissions at congested and uncongested intersections with motor vehicle emission simulation 2010," Transportation Research Record, no. 2270, pp. 124-131, 2012.

[27] L. Vasconcelos, A. Silva, Á. Seco, P. Fernandes, and M. Coelho, "Turboroundabouts: multicriterion assessment of intersection capacity, safety, and emissions," Transportation Research Record, no. 2402, pp. 28-37, 2014.

[28] P. Fernandes, K. Salamati, N. M. Rouphail, and M. C. Coelho, "Identification of emission hotspots in roundabouts corridors," Transportation Research Part D: Transport and Environment, vol. 37, pp. 48-64, 2015.

[29] P. Fernandes, N. M. Rouphail, and M. C. Coelho, "Turboroundabouts along corridors: Analysis of operational and environmental impacts," Transportation Research Record, vol. 2627, pp. 46-56, 2017.

[30] J.-Q. Li, G. Wu, and N. Zou, "Investigation of the impacts of signal timing on vehicle emissions at an isolated intersection," Transportation Research Part D: Transport and Environment, vol. 16, no. 5, pp. 409-414, 2011.

[31] J. Song, S. Hu, and K. Han, "Real-time adaptive traffic signal control: trade-off between traffic and environment objectives," in Proceedings of the 96th Annual Meeting of the Transportation Research Board, Washington, DC, USA, 2017.

[32] A. J. Calle Laguna, H. A. Rakha, and J. Du, "Comprehensive analysis on signal timing optimization to reduce energy and environmental impacts," in Proceedings of the 96th Annual Meeting of the Transportation Research Board, Washington, DC, USA, 2017.

[33] G. Meccariello, L. Della R., M. V. Prati, M. A. Costagliola, and V. Saccoccia, "Real Time Emissive Behaviour of a Bi-Fuel Euro 4
SI Car in Naples Urban Area," SAE International Journal of Fuels and Lubricants, vol. 6, no. 3, 2013.

[34] H. C. Frey, A. Unal, N. M. Rouphail, and J. D. Colyar, "Onroad measurement of vehicle tailpipe emissions using a portable instrument," Journal of the Air \& Waste Management Association, vol. 53, no. 8, pp. 992-1002, 2003.

[35] A. Unal, H. C. Frey, and N. M. Rouphail, "Quantification of Highway Vehicle Emissions Hot Spots Based upon OnBoard Measurements," Journal of the Air \& Waste Management Association, vol. 54, no. 2, pp. 130-140, 2004.

[36] H. Rakha, F. Dion, and H. Sin, "Using Global Positioning System Data for Field Evaluation of Energy and Emission Impact of Traffic Flow Improvement Projects: Issues and Proposed Solutions," Transportation Research Record, vol. 1768, pp. 210223, 2001.

[37] L. Salmaso and A. Solari, "Multiple aspect testing for casecontrol designs," Metrika, vol. 62, no. 2-3, pp. 331-340, 2005.

[38] F. Pesarin and L. Salmaso, Permutation Tests for Complex Data: Theory, Applications and Software, John Wiley and Sons, Chichester, UK, 2010.

[39] R. A. Giancristofaro and S. Bonnini, "Moment-based multivariate permutation tests for ordinal categorical data," Journal of Nonparametric Statistics, vol. 20, no. 5, pp. 383-393, 2008.

[40] R. Arboretti Giancristofaro and S. Bonnini, "Some new results on univariate and multivariate permutation tests for ordinal categorical variables under restricted alternatives," Statistical Methods and Applications, vol. 18, no. 2, pp. 221-236, 2009.

[41] R. Arboretti Giancristofaro, S. Bonnini, and F. Pesarin, "A permutation approach for testing heterogeneity in two-sample categorical variables," Statistics and Computing, vol. 19, no. 2, pp. 209-216, 2009.

[42] R. A. Giancristofaro, "Permutation solutions for multivariate ranking and testing with applications," Communications in Statistics-Theory and Methods, vol. 43, no. 4, pp. 891-905, 2014.

[43] C. Meneguzzer and R. Rossi, "Evaluating the impact of pedestrian crossings on roundabout entry capacity," Procedia Social \& Behavioral Sciences, vol. 20, pp. 69-78, 2011.

[44] C. Meneguzzer and R. Rossi, "Analysis and control of the interaction between vehicular and pedestrian flows on roundabout approaches," European Transport - Trasporti Europei, vol. 53, no. 9, pp. 1-16, 2013.

[45] E. Wygonik and A. Goodchild, "Evaluating $\mathrm{CO}_{2}$ emissions, cost, and service quality trade-offs in an urban delivery system case study," IATSS Research, vol. 35, no. 1, pp. 7-15, 2011.

[46] F. Russo and A. Comi, "Urban freight transport planning towards green goals: Synthetic environmental evidence from tested results," Sustainability, vol. 8, no. 4, article no. 381, 2016. 


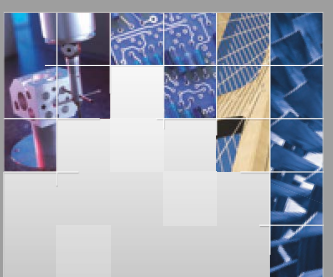

\section{Enfincering}
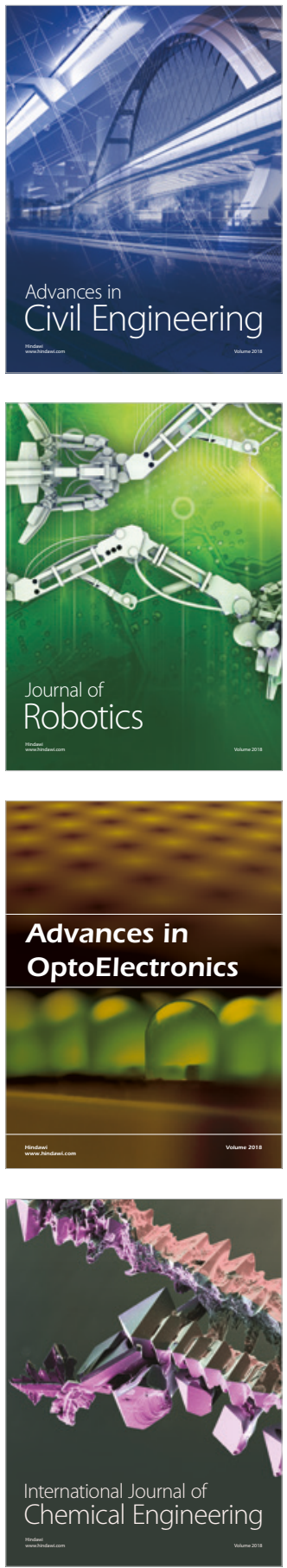

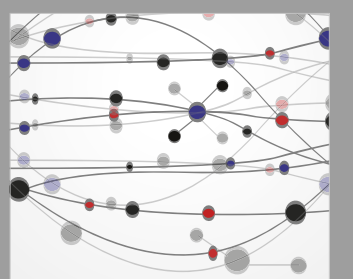

\section{Rotating \\ Machinery}

The Scientific World Journal

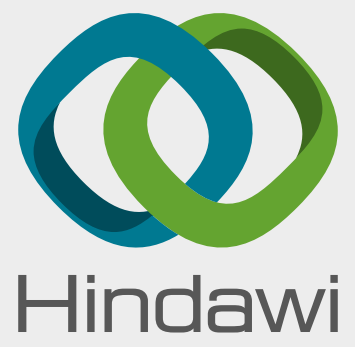

Submit your manuscripts at

www.hindawi.com
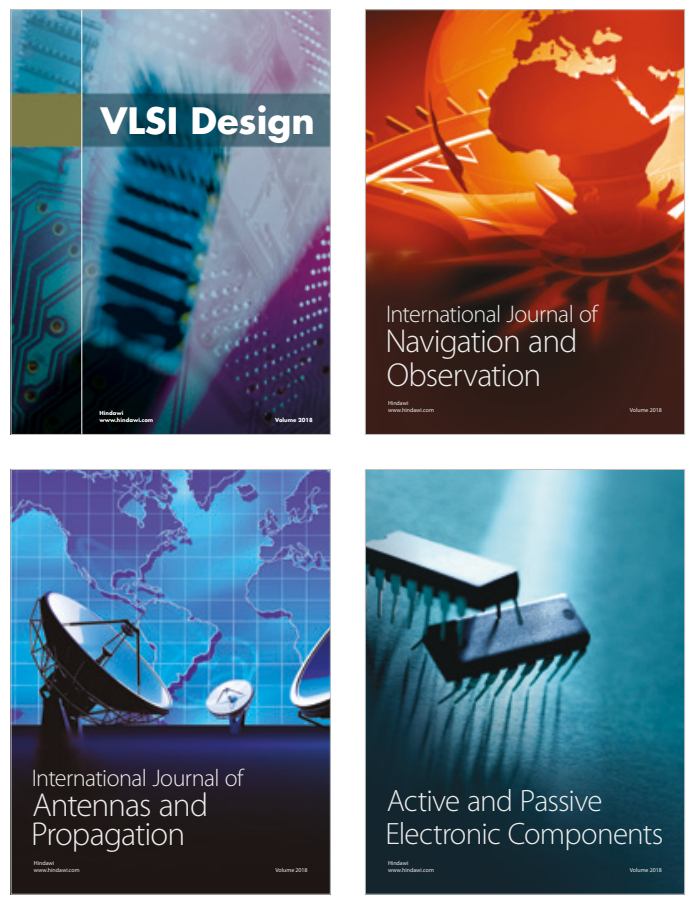
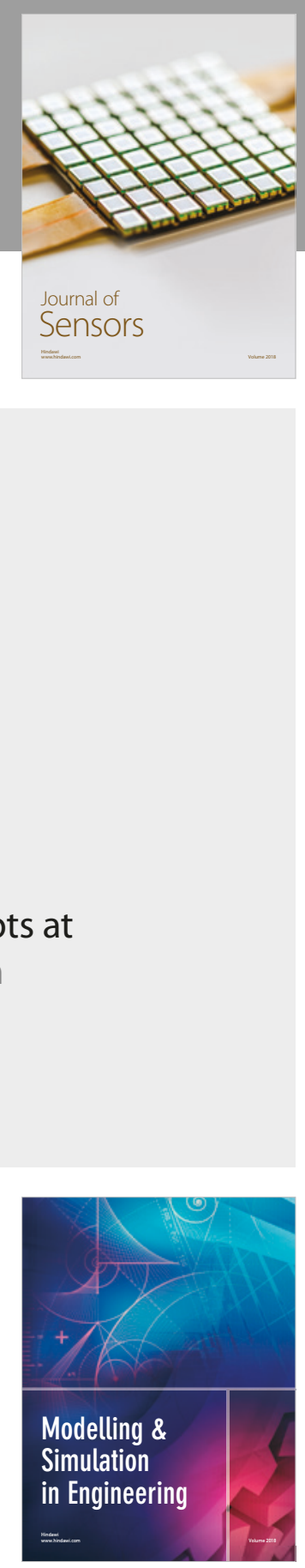

\section{Advances \\ Multimedia}
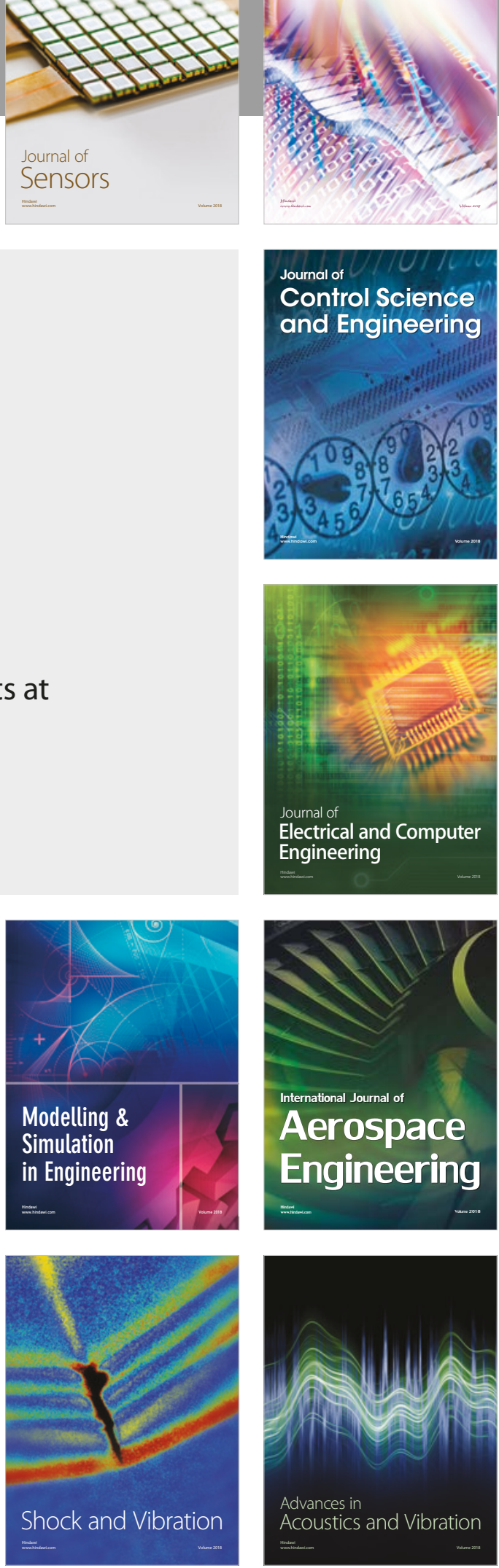